\title{
Is there a bidirectional relationship between depressive symptoms and cognitive ability in older people? A prospective study using the English Longitudinal Study of Ageing
}

\author{
C. R. Gale ${ }^{1,2 *}$, M. Allerhand ${ }^{2}$ and I. J. Deary ${ }^{2}$ for the HALCyon Study Team \\ ${ }^{1}$ MRC Lifecourse Epidemiology Unit, University of Southampton, Southampton, UK \\ ${ }^{2}$ Centre for Cognitive Ageing and Cognitive Epidemiology, Department of Psychology, University of Edinburgh, Edinburgh, UK
}

\begin{abstract}
Background. Cross-sectional surveys of older people commonly find associations between higher levels of depressive symptoms and poorer cognitive performance, but the direction of effect is unclear. We examined whether there was a bidirectional relationship between depressive symptoms and general cognitive ability in non-demented older people, and explored the role of physical health, smoking, exercise, social class and education as potential confounders of this association and as possible determinants of the rate of change of cognitive decline and depressive symptoms.
\end{abstract}

Method. The English Longitudinal Study of Ageing consists of people aged 50 years and over. Cognitive function and self-reported depressive symptoms were measured in 2002-2003, 2004-2005, 2006-2007 and 2008-2009. We fitted linear piecewise models with fixed knot positions to allow different slopes for different age groups. Analyses are based on 8611 people.

Results. Mean cognitive function declined with age; there was no trend in the trajectory of depressive symptoms. Better cognitive function was associated with less depression up to the age of 80 years. Greater depression was associated with a slightly faster rate of cognitive decline but only in people aged 60-80 years. There were no consistent associations across age groups between sex, smoking, education, social class, exercise or number of chronic physical illnesses and the rate of change of cognitive decline or depressive symptoms.

Conclusions. In this longitudinal study of older people, there was no consistent evidence that being more depressed led to an acceleration in cognitive decline and no support for the hypothesis that there might be reciprocal dynamic influences between cognitive ability and depressive symptoms.

Received 1 June 2011; Revised 3 February 2012; Accepted 7 February 2012; First published online 15 March 2012

Key words: Ageing, cognition, cognitive decline, depressive symptoms.

\section{Introduction}

There is considerable evidence from cross-sectional studies of older people that depression and poorer cognitive performance often coexist. Higher scores on self-rating measures of depressive symptoms such as the Center for Epidemiologic Studies Depression Scale (CES-D), the Hospital Anxiety and Depression Scale, the Beck Depression Inventory or the Geriatric Mental State Schedule have been associated with lower scores on measures of fluid-type cognitive ability (Scherr et al. 1988; La Rue et al. 1995; Rabbitt et al. 1995;

* Address for correspondence: C. R. Gale, Ph.D., MRC Lifecourse Epidemiology Unit (University of Southampton), Southampton General Hospital, Southampton SO16 6YD, UK.

(Email: crg@mrc.soton.ac.uk)
Gale et al. 2011) and on cognitive screening tests such as the Mini-Mental State Examination (MMSE) (Kay et al. 1985; Fuhrer et al. 1992; Auperin et al. 1996; Mangione et al. 1993). Fluid-type cognitive ability tests involve the carrying out of active mental work and not just recalling knowledge. The association between depression and poorer cognition is not confined to older people. Christensen et al. (1997) carried out a meta-analysis of studies that compared the cognitive performance of people with depression (either clinically diagnosed or with high scores on self-rating measures) with non-depressed controls and found that the presence of depression was associated with deficits on a wide range of standard cognitive tests, involving speed, attention, tracking and conceptual tasks. These deficits were present in people aged under 60 years as well as in older individuals, though

The online version of this article is published within an Open Access environment subject to the conditions of the Creative Commons Attribution-NonCommercial-ShareAlike licence <http://creativecommons.org/licenses/by-nc-sa/2.5/ $>$. The written permission of Cambridge University Press must be obtained for commercial re-use. 
the magnitude of the effect size tended to be greater at older ages.

The cause of the cross-sectional associations between depression and poorer cognitive function in older people is uncertain. One possibility is that depressive symptoms may be a risk factor for cognitive decline. Some studies have found that high scores on the CES-D are associated with an increased risk of developing dementia (Wilson et al. 2002; Gatz et al. 2005), but evidence that elevated levels of depressive symptoms are predictive of cognitive decline in older people without dementia is inconsistent. Ganguli et al. (2006) studied over 1200 such individuals using the CES-D and composite scores from a battery of cognitive tests, all of which were administered biennially, and found no link between depressive symptoms and rate of cognitive decline over 12 years. In a study of 1600 people using the CES-D and a cruder measure of cognitive decline, decrease in MMSE score of $\geqslant 5$ points over 3 years, Dufouil et al. (1996) found no association between depressive symptoms and risk of cognitive deterioration. Several larger longitudinal studies have found associations between higher levels of depressive symptoms assessed with the CES-D or the Geriatric Depression Scale and cognitive decline (Yaffe et al. 1999; Paterniti et al. 2002; Wilson et al. 2004). One of these studies assessed cognitive function at 3-yearly intervals for an average of 5 years using four tests of fluid ability from which a composite measure was derived (Wilson et al. 2004). However, in the other two studies cognitive change was assessed over only two time points and was based wholly (Paterniti et al. 2002) or partly on the MMSE (Yaffe et al. 1999). Some longitudinal studies have found associations between depressive symptoms assessed using the CES-D or Geriatric Depression Scale and subsequent cognitive decline assessed using the MMSE or other screening questionnaires in subgroups only: for example, in men ( $\mathrm{Ng}$ et al. 2009), or in the more highly educated (Geerlings et al. 2000), or in those who are already cognitively impaired (Bassuk et al. 1998). The use of single crude cognitive tests coupled with the fact that several studies are based on only two time points or a short follow-up period (Dufouil et al. 1996; Henderson et al. 1997; Yaffe et al. 1999; Ng et al. 2009) may have affected the robustness with which cognitive change was measured.

Few studies have investigated whether the crosssectional associations between depression and poorer cognition in older people reflect the effect of poor cognition on mood. No association was found between low MMSE score and incident depression in the Longitudinal Ageing Study Amsterdam (de Beurs et al. 2001). However, better overall performance on five cognitive tests predicted an improvement in depressive symptoms in one cohort (Fonda \& Herzog, 2001). In another small study that examined the relationship between cognitive function and depressive symptoms over four time points, poorer cognitive function predicted greater depressive symptoms at all subsequent time points (Perrino et al. 2008).

In the present study we used piecewise linear mixed-effects models of data from four waves of the English Longitudinal Study of Ageing (ELSA) to investigate whether level of depressive symptoms predicted the rate of cognitive decline in communitydwelling, non-demented people and whether general cognitive ability predicted the trajectory of depressive symptoms.

We investigated whether physical health (Bond et al. 2006; Chang-Quan et al. 2010), smoking (Nooyens et al. 2008), exercise (Kramer et al. 2006; Blake et al. 2009), social class or education (Anstey \& Christensen, 2000; Koster et al. 2005, 2006) confounded any association and explored the role of these factors in determining trajectories of cognitive decline and depressive symptoms.

\section{Method}

\section{Participants}

The sample for the ELSA was based on people aged $\geqslant 50$ years who had participated in the Health Survey for England in 1998, 1999 or 2001 (Marmot et al. 2011). It was drawn by postcode sector, stratified by health authority and proportion of households in nonmanual socio-economic groups. A total of 11392 people participated in the first survey in 2002-2003. There were further waves in 2004-2005, 2006-2007 and 2008-2009. Ethical approval was obtained from the Multicentre Research and Ethics Committee. Participants gave written informed consent.

\section{Measures \\ Cognitive function}

Cognitive function was assessed at waves 1-4 using tests of immediate and delayed verbal memory (recall of 10 aurally presented nouns), prospective memory (remembering to do a specific task), verbal (semantic) fluency (naming as many animals as possible in $60 \mathrm{~s}$ ) and attention (letter cancellation task) (Marmot et al. 2011).

We derived a cognition score at each wave using principal components analyses of the five cognitive measurements. Scree plots suggested the presence of a single component on each occasion. A general cognitive score (g-factor) was calculated at each wave using a multiple indicator measurement model 
(Mplus, version 6.1; Muthén \& Muthén, 1998-2010). The model was constrained by requiring corresponding factor loadings across waves to be equal on the assumption of measurement invariance. The direction of the scale was adjusted so that increasing factor score corresponded with increasing cognitive ability. The g-factor was scaled into conventional intelligence quotient (IQ) units (mean 100, s.D.=15). Scaling into conventional IQ units was based on the subsample of participants aged less than 60 years. This subsample was considered to be normative. This scaling was then applied to the g-factor for all participants.

\section{Depressive symptoms}

Symptoms of depression were assessed at waves 1-4 using an eight-item version of the CES-D (Steffick, 2000). Participants were asked to think about the last week and the feelings they experienced and to indicate whether each of the following statements was true for them much of the time during the last week: you felt depressed; you felt that everything was an effort; your sleep was restless; you were happy; you felt lonely; you enjoyed life; you felt sad; you could not get going. There were two response options: yes or no. This version of the CES-D has an internal consistency and factor structure that are comparable with longer versions of the scale (Turvey et al. 1999).

We derived a depression score at each wave by summing the items. The data were log transformed to reduce the skew in the sample in which the majority of people did not have much depressive symptomatology. The scores at each wave were scaled into units of standard deviation at wave 1 , and the mean score at each wave was measured from the mean score at wave 1 .

\section{Covariates}

We used sex, age at finishing full-time education, social class, smoking status, physical health and exercise as covariates. Information on education and social class - based on current or most recent job classified according to the National Statistics Socioeconomic Classification (Office for National Statistics, 2005) was collected at the initial interview. During wave 1 participants were asked whether a doctor had ever told them that they had any of the following conditions: high blood pressure/hypertension, angina, heart attack, congestive heart failure, diabetes or high blood sugar, a stroke, chronic lung disease, asthma, arthritis or rheumatism, osteoporosis, or cancer. We added the number of chronic conditions present to get a measure of physical health. At wave 1 participants also provided information about their current smoking habits. Participants also responded to three questions about frequency of vigorous, moderate or mild exercise. We ranked the combinations of responses to these questions according to the amount and intensity of exercise involved and grouped them into quarters of the distribution. Details are available on request.

\section{Analytical sample}

We excluded individuals who had no data on any of the variables of interest, and 126 people who had reported by wave 1 that a doctor had told them that they had Parkinson's disease, Alzheimer's disease, dementia, organic brain syndrome or serious memory impairment. This left 8611 cases.

Table 1 shows the characteristics of the participants at each wave as regards age, interval between waves and the covariates. There was attrition over time; however, the proportions of the response levels within each covariate remained reasonably constant across waves. We therefore conclude that the pattern of missingness does not introduce systematic bias; however, as a further check, we also carried out a sensitivity analysis to see whether the pattern of missingness affected the results of our models, following the procedure described by Hedeker \& Gibbons (1997). Results of this are given below.

\section{Statistical analysis}

Measurements of cognition and depressive symptoms were made four times over a period of 6 years. Everyone in the sample was measured at roughly the same time (within a year of each other), at roughly the same 2-year intervals. However, people entering the study ranged in age from 50 to over 90 years. Consequently, results may to some extent be confounded by period and birth cohort effects, as well as the usual effects of selective drop-out. One approach would be to control for individual birth date in a model of the overall trajectory of cognition or depressive symptoms. However, we aim to expose the possibility that associations are different at different ages. These would be averaged by an overall polynomial trajectory. Instead, the analytic approach here is to fit linear piecewise models with fixed knot positions to allow different slopes for different age groups. Piecewise linear means that a curved trajectory can be closely approximated by a sequence of straight segments. It is called 'piecewise' because the segments are linear pieces of the whole trajectory. The segments join at 'change-points' along the trajectory. These are called 'knots' in spline terminology. It is 
Table 1. Summary characteristics of the participants at each measurement wave: age, interval between waves and the covariates

\begin{tabular}{|c|c|c|c|c|}
\hline & Wave 1 & Wave 2 & Wave 3 & Wave 4 \\
\hline Subjects, $n$ & 8611 & 8242 & 7150 & 6300 \\
\hline \multicolumn{5}{|l|}{ Age, years } \\
\hline Mean (s.D.) & $64.07(9.48)$ & $66.41(9.49)$ & $67.84(9.33)$ & $69.44(8.98)$ \\
\hline Range & $50-90$ & $52-92$ & $54-94$ & $56-95$ \\
\hline Mean interval, years (S.D.) & & $2.3(0.46)$ & $1.82(0.44)$ & $2.08(0.42)$ \\
\hline \multicolumn{5}{|l|}{ Sex, $n(\%)$} \\
\hline Female & $4760(55.3)$ & $4559(55.3)$ & $3976(55.6)$ & $3538(56.2)$ \\
\hline Male & $3851(44.7)$ & $3683(44.7)$ & $3174(44.4)$ & $2762(43.8)$ \\
\hline \multicolumn{5}{|l|}{ Smoking, $n(\%)$} \\
\hline Current smoker & $1494(17.3)$ & $1416(17.2)$ & $1200(16.8)$ & $1026(16.3)$ \\
\hline Ex-smoker & $4006(46.5)$ & $3840(46.6)$ & $3313(46.3)$ & $2899(46.0)$ \\
\hline Never smoked & $3111(36.1)$ & $2986(36.2)$ & $2637(36.9)$ & $2375(37.7)$ \\
\hline \multicolumn{5}{|l|}{ Social class, $n(\%)$} \\
\hline Professional & $408(4.8)$ & $392(4.8)$ & $358(5.1)$ & $325(5.3)$ \\
\hline Managerial/technical & $2485(29.4)$ & $2394(29.6)$ & $2131(30.4)$ & $1939(31.4)$ \\
\hline Skilled non-manual & $2099(24.9)$ & $2025(25)$ & $1769(25.2)$ & $1572(25.4)$ \\
\hline Skilled manual & $1636(19.4)$ & $1551(19.2)$ & $1311(18.7)$ & 1109 (17.9) \\
\hline Semi-skilled manual & $1264(15.0)$ & $1204(14.9)$ & $1027(14.6)$ & $886(14.3)$ \\
\hline Unskilled manual & $548(6.5)$ & $518(6.4)$ & $420(6.0)$ & $352(5.7)$ \\
\hline \multicolumn{5}{|c|}{ Age (years) finished full-time education, $n(\%)$} \\
\hline Never went to school & $26(0.3)$ & $24(0.3)$ & $23(0.3)$ & $22(0.4)$ \\
\hline$\leqslant 14$ & $1753(20.8)$ & $1672(20.8)$ & $1381(19.8)$ & $1114(18.1)$ \\
\hline 15 & $2892(34.4)$ & $2751(34.2)$ & $2354(33.7)$ & $2105(34.2)$ \\
\hline 16 & $1557(18.5)$ & $1499(18.6)$ & $1316(18.8)$ & $1176(19.1)$ \\
\hline 17 & $635(7.5)$ & $605(7.5)$ & $546(7.8)$ & $499(8.1)$ \\
\hline 18 & $442(5.3)$ & $425(5.3)$ & $377(5.4)$ & $344(5.6)$ \\
\hline$\geqslant 19$ & $1109(13.2)$ & $1075(13.4)$ & $987(14.1)$ & $896(14.6)$ \\
\hline \multicolumn{5}{|c|}{ No. of chronic illnesses, $n(\%)$} \\
\hline 0 & $2665(31.0)$ & $2554(31.0)$ & $2270(31.8)$ & $2051(32.6)$ \\
\hline 1 & $2875(33.4)$ & $2728(33.1)$ & $2360(33)$ & $2121(33.7)$ \\
\hline 2 & $1806(21.0)$ & $1746(21.2)$ & $1499(21.0)$ & $1299(20.6)$ \\
\hline 3 & $763(8.9)$ & $727(8.8)$ & $634(8.9)$ & $522(8.3)$ \\
\hline 4 & $311(3.6)$ & $305(3.7)$ & $251(3.5)$ & $214(3.4)$ \\
\hline 5 & 115 (1.3) & 109 (1.3) & $79(1.1)$ & $57(0.9)$ \\
\hline 6 & $55(0.6)$ & $54(0.7)$ & $44(0.6)$ & $26(0.4)$ \\
\hline 7 & $11(0.1)$ & $10(0.1)$ & $7(0.1)$ & $5(0.1)$ \\
\hline 8 & $5(0.1)$ & $4(0)$ & $2(0)$ & $1(0)$ \\
\hline \multicolumn{5}{|l|}{ Exercise, $n(\%)$} \\
\hline \multirow[t]{3}{*}{ Low } & $2724(31.7)$ & $2599(31.6)$ & $2173(30.4)$ & $1813(28.8)$ \\
\hline & $2582(30.0)$ & $2470(30.0)$ & $2146(30.1)$ & $1911(30.4)$ \\
\hline & $1632(19.0)$ & $1571(19.1)$ & $1396(19.6)$ & $1273(20.2)$ \\
\hline High & 1659 (19.3) & $1589(19.3)$ & $1422(19.9)$ & $1291(20.5)$ \\
\hline
\end{tabular}

S.D., Standard deviation.

sometimes called a 'broken-stick' model because that is what the approximated trajectory would look like. The knots are located at change-points in a functional trajectory, such that the trajectory between the knots is reasonably linear. The overall trajectories for cognition and depressive symptoms were found by fitting additive mixed models to the longitudinal data
(Hastie \& Tibsharani, 1999; Ruppert et al. 2003; Woods, 2006).

This semi-parametric method estimates a functional trajectory based on penalized regression splines within a mixed model framework. The method is appropriate when the longitudinal response is potentially non-linear. It is an essentially exploratory approach 
for uncovering non-linear trends without having to specify a model in terms of detailed and unknown parametric relationships. An interaction (Ruppert et al. 2003) was used to generate smooth trajectories at each level of a grouping factor. A dummy variable was created from the CES-D data to indicate two groups of depression scores (low and high). Its purpose was to test the difference in the effect of these two groups on the cognitive growth parameters. We dichotomized the summary score using a cut-point of 4 or higher, which is equivalent to the conventional cut-point of 16 or higher on the full 20-item CES-D (Steffick, 2000). The high-depression group contains those people whose depressive symptom score was 4 or higher. We also created a dummy variable from the cognition data to indicate two groups of cognitive function scores (low and high) in order to test the difference in the effect of these two groups on the depression growth parameters. The grouping was based on the average within-person cognition score and was obtained separately within each age group to capture change over the longer term between age groups. The lowcognition group contains those people whose cognition score was below the median score within that cohort, and vice versa for the high-cognition group. The subsequent piecewise analysis of the trajectories of cognition and depressive symptoms was based on a division into segments defining three age groups: 50-60 $(n=2552), 60-80(n=5070)$ and 80-90 $(n=989)$ years. The age-group cut-points are driven by the spline fits. These show the trajectory changes at around age 60 and age 80 years. Between these ages the trajectory is acceptably linear. Subjects are assigned to age groups by their average age within the study. Thus, the boundary between age groups is a little fuzzy and the overlap can be put down to rounding.

There may be uncontrolled cohort effects confounding comparisons across age groups, but we expect these to be small relative to the effects of interest. Analysis within age groups is conventional linear mixed effects for longitudinal data. Comparisons across age groups are necessarily cross-sectional (and hence potentially confounded by individual differences) due to the fact that the time spans between them are greater than the 6-year study period. However, we controlled for variation due to individual differences in a range of covariates. These covariates are used in the complex sampling design to estimate longitudinal weights for non-response. Our models incorporate longitudinal weighting through the addition of these covariates. Parameters of the models were estimated using $\mathrm{R}$ function $\operatorname{lmer}(\operatorname{lme} 4)$, version 0.999375-37 (http://lme4.r-forge.r-project.org/), with full maximum likelihood. Estimates, confidence intervals (CIs), $p$ values and significance stars were obtained using Markov chain Monte Carlo (R function pvals.fnc\{languageR $\}$, version 1.0).

The relative goodness of fit of the models is indicated by their deviance, Akaike's Information Criterion and Bayesian Information Criterion.

\section{Results}

Table 2 shows regression coefficients (95\% CIs) from the piecewise linear mixed-effects models of cognition in the three age groups. Looking first at initial status, the intercept is the predicted average cognition score - scaled into conventional IQ units - at baseline, with all other covariates held at zero. In each age group time is centred on the age at the start of that group. Therefore these intercepts represent the modelpredicted average cognition score at ages 50,60 and 80 , respectively. Average cognition score is lower in each successive age group, falling by about 22 points between the ages of 50 and 80 years - approximately 1.5 of a standard deviation. People in the highdepression group have significantly poorer cognition on average than those in the low-depression group when all other covariates are held at zero, although this difference is not present in the oldest age group. Among people aged 60-80 years, those whose depression score was 4 or more have a cognition score that is an average of 4.4 points below those in the lowdepression group, which is -0.29 of a standard deviation. High depression was associated with a slightly smaller difference in cognition in the youngest age group. Independently of this, cognition scores were significantly lower in men, in those from a lower social class or with fewer years of full-time education, in those with more chronic illnesses, and in those who took less exercise. In general, these associations were similar in each age group, though the associations between lower average cognition and poorer physical health or taking less exercise were much stronger in those aged 80-90 years than in those aged 50-60 years. There was no consistent association between cognition and smoking status. We examined whether the relationship between average cognition at baseline and depression varied according to levels of the covariates. In general, there were no significant interaction terms that were present consistently in each age group.

Looking now at rate of change in general cognition, the intercept is the average slope of cognition-on-time with all covariates held at zero. In people aged 50-60 years, on average cognition remains stable over the follow-up period, but there is a significant decline in cognition among those aged 60-80 years (nearly 0.5 points per year) and this accelerates in the oldest age group to 1.08 points per year. There was no significant difference in the rate of cognitive decline between 
Table 2. Results from piecewise linear mixed-effects models of cognition in three age groups ${ }^{a}$

\begin{tabular}{|c|c|c|c|c|}
\hline & & Age $50-60$ years $(n=2552)$ & Age $60-80$ years $(n=5070)$ & Age $80-90$ years $(n=989)$ \\
\hline \multicolumn{5}{|l|}{ Fixed effects } \\
\hline \multirow[t]{14}{*}{ Initial status } & Intercept $^{\mathrm{b}}$ & 99.62 (99.01 to 100.20$)^{* * *}$ & 96.32 (96.01 to 96.67$)^{* * *}$ & $76.73(75.85 \text { to } 77.52)^{* * *}$ \\
\hline & Depression & $-2.33(-4.38 \text { to }-0.25)^{*}$ & $-4.37(-5.98 \text { to }-2.86)^{* * *}$ & $0.43(-3.19$ to 4.05$)$ \\
\hline & Male & $-1.54(-1.98 \text { to }-1.07)^{* * *}$ & $-2.94(-3.27 \text { to }-2.61)^{* * *}$ & $-1.50(-2.26 \text { to }-0.70)^{* * *}$ \\
\hline & Smoking ${ }^{c}$ & $-0.75(-1.19 \text { to }-0.3)^{* * *}$ & $0.32(-0.028$ to 0.63$)$ & $-0.09(-0.99$ to 0.80$)$ \\
\hline & Social class ${ }^{c}$ & $-3.17(-3.68 \text { to }-2.70)^{* * *}$ & $-3.55(-3.89 \text { to }-3.19)^{* * *}$ & $-3.72(-4.61 \text { to }-2.88)^{* * *}$ \\
\hline & Age left education ${ }^{c}$ & $3.24(2.69 \text { to } 3.77)^{* * *}$ & $3.21(2.84 \text { to } 3.60)^{* * *}$ & $2.99(2.07 \text { to } 3.86)^{* * *}$ \\
\hline & No. of chronic illnesses ${ }^{c}$ & $-0.63(-1.33$ to 0.02$)$ & $-0.82(-1.16 \text { to }-0.478)^{* * *}$ & $0.74(0.02 \text { to } 1.4)^{*}$ \\
\hline & Exercise $^{c}$ & $0.98(0.49 \text { to } 1.43)^{* * *}$ & $0.98(0.63 \text { to } 1.26)^{* * *}$ & $1.94(1.09 \text { to } 2.79)^{* * *}$ \\
\hline & Depression-sex & $1.81(-0.01 \text { to } 3.43)^{*}$ & $2.70(1.44 \text { to } 4.21)^{* *}$ & $-2.00(-4.71$ to 0.52$)$ \\
\hline & Depression-smoking & $1.19(-0.23$ to 2.72$)$ & $0.08(-1.09$ to 1.23$)$ & $2.39(-0.05$ to 5.17$)$ \\
\hline & Depression-social class & $-1.60(-3.38$ to 0.20$)$ & $0.02(-1.40$ to 1.27$)$ & $4.24(1.31 \text { to } 6.53)^{* * *}$ \\
\hline & Depression-age left education & $-1.02(-3.16$ to 1.22$)$ & $-0.48(-2.20$ to 1.48$)$ & $2.75(-0.062$ to 5.64$)$ \\
\hline & Depression-chronic illnesses & 0.15 ( -1.61 to 2.07$)$ & $0.53(-0.56$ to 1.58$)$ & $-0.23(-1.83$ to 1.50$)$ \\
\hline & Depression-exercise & 0.55 ( -1.28 to 2.48$)$ & $1.02(-0.41$ to 2.43$)$ & $3.78(0.88 \text { to } 6.28)^{*}$ \\
\hline \multirow[t]{14}{*}{ Rate of change } & Intercept $^{\mathrm{d}}$ & $0.24(0.12 \text { to } 0.34)^{* * *}$ & $-0.58(-0.64 \text { to }-0.53)^{* * *}$ & $-1.43(-1.67 \text { to }-1.21)^{* * *}$ \\
\hline & Depression & $-0.21(-0.63$ to 0.20$)$ & $-0.26(-0.5 \text { to }-0.02)^{*}$ & $0.02(-0.84$ to 0.93$)$ \\
\hline & Male & $-0.10(-0.21$ to -0.01$)$ & $0.02(-0.03$ to 0.08$)$ & $0.05(-0.14$ to 0.24$)$ \\
\hline & Smoking ${ }^{c}$ & $0.10(0.03 \text { to } 0.20)^{*}$ & $0.02(-0.04$ to 0.07$)$ & $-0.04(-0.28$ to 0.18$)$ \\
\hline & Social class ${ }^{c}$ & $-0.07(-0.18$ to 0.04$)$ & $-0.01(-0.06$ to 0.05$)$ & $0.04(-0.18$ to 0.24$)$ \\
\hline & Age left education $^{c}$ & $0.08(-0.02$ to 0.19$)$ & $0.12(0.06 \text { to } 0.17)^{* * * *}$ & $0.07(-0.14$ to 0.28$)$ \\
\hline & No. of chronic illnesses ${ }^{c}$ & $-0.05(-0.19$ to 0.08$)$ & $-0.02(-0.07$ to 0.04$)$ & $-0.002(-0.18$ to 0.18$)$ \\
\hline & Exercise $^{c}$ & $0.03(-0.06$ to 0.12$)$ & 0.05 (0.002 to 0.11$)$ & $-0.07(-0.28$ to 0.14$)$ \\
\hline & Depression-sex & $-0.15(-0.49$ to 0.25$)$ & $-0.40(-0.61 \text { to }-0.20)^{* * *}$ & $0.16(-0.55$ to 0.75$)$ \\
\hline & Depression-smoking & $-0.06(-0.35$ to 0.25$)$ & $-0.07(-0.25$ to 0.11$)$ & $-0.10(-0.70$ to 0.55$)$ \\
\hline & Depression-social class & $-0.01(-0.41$ to 0.33$)$ & $0.02(-0.18$ to 0.21$)$ & $-0.20(-0.87$ to 0.45$)$ \\
\hline & Depression-age left education & $0.13(-0.38$ to 0.62$)$ & $-0.15(-0.40$ to 0.10$)$ & $0.14(-0.58$ to 0.89$)$ \\
\hline & Depression-chronic illnesses & $0.16(-0.21$ to 0.570$)$ & $0.04(-0.19$ to 0.19$)$ & $0.07(-0.33$ to 0.52$)$ \\
\hline & Depression-exercise & $-0.06(-0.45$ to 0.35$)$ & $0.11(-0.1$ to 0.35$)$ & $0.03(-0.70$ to 0.72$)$ \\
\hline \multicolumn{5}{|c|}{ Variance components ${ }^{\mathrm{e}}$} \\
\hline Level 1 & Within-person & 27.65 & 30.07 & 25.17 \\
\hline Level 2 & In initial status & 144.08 & 147.83 & 195.93 \\
\hline Level 2 & In rate of change & 0.75 & 0.74 & 1.65 \\
\hline
\end{tabular}




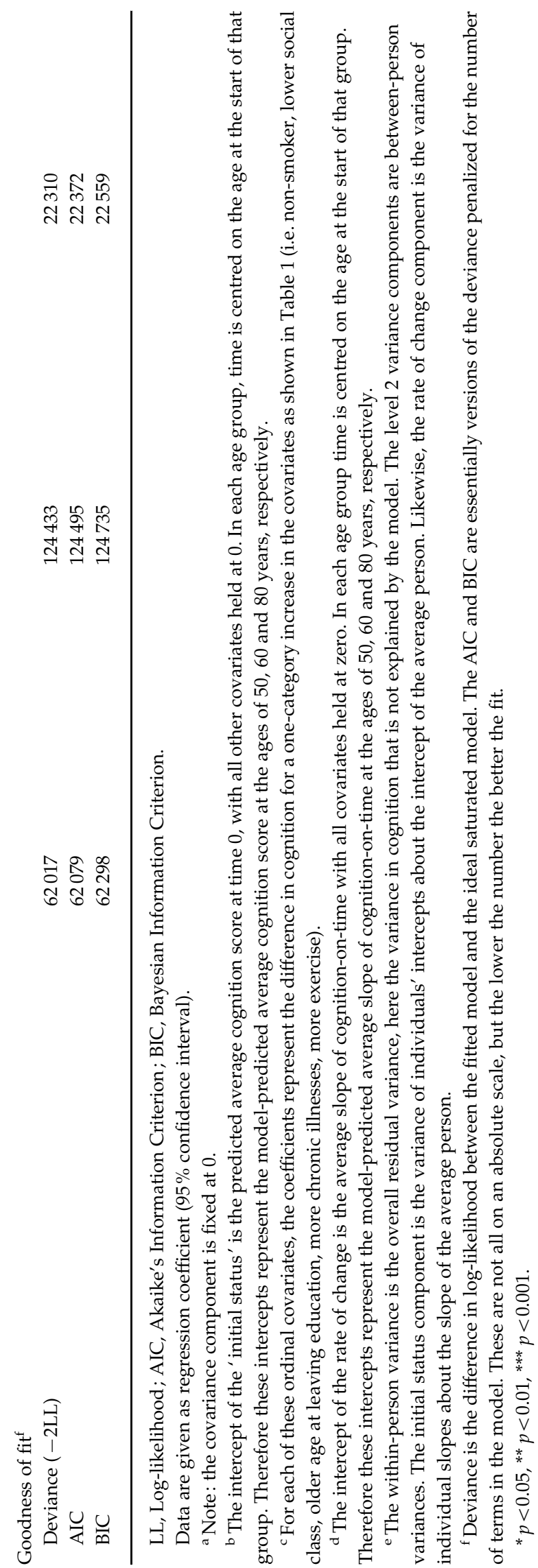

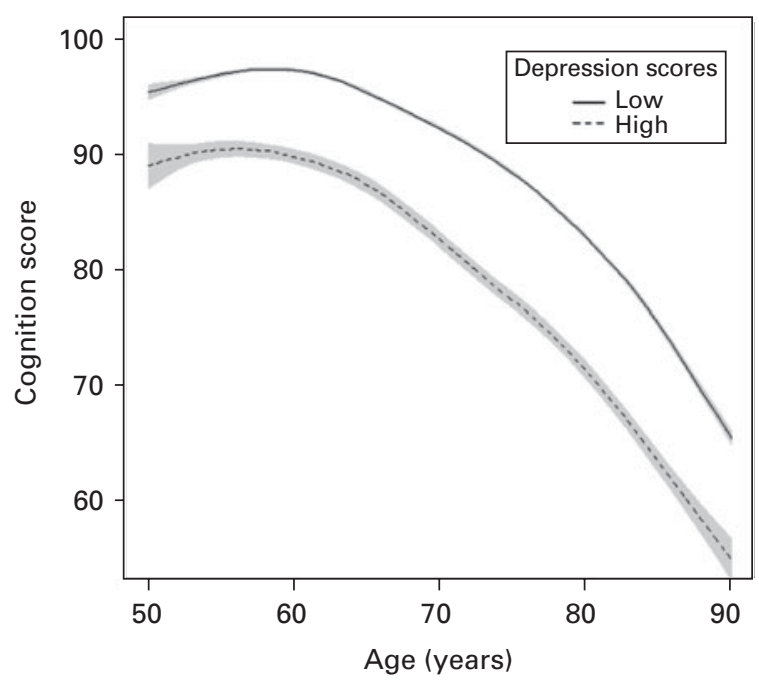

Fig. 1. Trajectories of cognitive decline by age with piecewise models for the two depression groups: low depression and high depression. Results are from the model without covariates.

people in the high- or low-depression groups, except in those aged 60-80 years where people with high depression scores had a slightly faster rate of decline (see also Fig. 1). There was a similar, though non-significant, effect size in the 50-60 years age group. There were no consistent associations across age groups between sex, smoking, education, social class, exercise or number of chronic illnesses and rate of cognitive decline, and no consistent evidence that the relation between depression and rate of cognitive decline varied according to levels of the covariates.

The variance components in the models of cognition in Table 2 suggest that the within-person (residual) variance is relatively stable between age groups compared with the between-person variance in initial status (intercept) and rate of change (slope). However, there is a trend across age groups of increasing variation between people in the linear growth parameters (the intercept and slope), suggesting that they vary more in older people.

Table 3 shows regression coefficients ( $95 \%$ CIs) from the piecewise linear mixed-effects models of depressive symptoms in the three age groups. Looking first at initial status, the intercept is the average depression score at baseline across age groups, when all other covariates are held at zero. There is no clear trend by age: depression scores are slightly lower at age 60-80 years than in those aged $50-60$ years, and go up slightly in the oldest age group. Depression scores are lower in people with above average cognition and the size of the association is similar across age groups, when all other covariates are held at zero, but it is not statistically significant in the oldest age group. 
Table 3. Results from piecewise linear mixed-effects models of depressive symptoms in three age groups ${ }^{a}$

\begin{tabular}{|c|c|c|c|c|}
\hline & & Age 50-60 $(n=2552)$ & Age $60-80(n=5070)$ & Age $80-90(n=989)$ \\
\hline \multicolumn{5}{|c|}{ Fixed effects } \\
\hline \multicolumn{5}{|c|}{ Initial status } \\
\hline & Intercept $\mathrm{t}^{\mathrm{b}}$ & $2.09(1.93 \text { to } 2.24)^{* * *}$ & $1.51(1.45 \text { to } 1.59)^{* * *}$ & $1.54(1.41 \text { to } 1.65)^{* * *}$ \\
\hline & Cognition & $-0.39(-0.52 \text { to }-0.19)^{* * *}$ & $-0.33(-0.43 \text { to }-0.21)^{* * *}$ & $-0.35(-0.94$ to 0.26$)$ \\
\hline & Male & $-0.32(-0.44 \text { to }-0.16)^{* * *}$ & $-0.15(-0.21 \text { to }-0.09)^{* * *}$ & $-0.37(-0.48 \text { to }-0.26)^{* * * *}$ \\
\hline & Smoking ${ }^{c}$ & $-0.39(-0.51 \text { to }-0.28)^{* * *}$ & $-0.14(-0.21 \text { to }-0.09)^{* * *}$ & $-0.19(-0.32 \text { to }-0.08)^{* *}$ \\
\hline & Social class ${ }^{c}$ & $0.19(0.05 \text { to } 0.33)^{* *}$ & $0.18(0.11 \text { to } 0.24)^{* * *}$ & $-0.004(-0.12$ to 0.10$)$ \\
\hline & Age left education ${ }^{c}$ & $-0.10(-0.26$ to 0.05$)$ & $-0.07(-0.15$ to 0.02$)$ & $-0.16(-0.28 \text { to }-0.04)^{* *}$ \\
\hline & No. of chronic illnesses ${ }^{c}$ & $0.48(0.30 \text { to } 0.64)^{* * *}$ & $0.46(0.40 \text { to } 0.53)^{* * *}$ & $0.24(0.15 \text { to } 0.33)^{* * *}$ \\
\hline & Exercise $^{c}$ & $-0.27(-0.4 \text { to }-0.14)^{* * *}$ & $-0.19(-0.25 \text { to }-0.13)^{* * *}$ & $-0.27(-0.40 \text { to }-0.17)^{* * *}$ \\
\hline & Cognition-sex & $0.12(-0.07$ to 0.29$)$ & $-0.04(-0.13$ to 0.07$)$ & $0.10(-0.55$ to 0.77$)$ \\
\hline & Cognition-smoking & $0.38(0.23 \text { to } 0.54)^{* * *}$ & $0.11(0.01 \text { to } 0.20)^{*}$ & $-0.42(-1.06$ to 0.23$)$ \\
\hline & Cognition-social class & $-0.14(-0.34$ to 0.05$)$ & $-0.16(-0.28 \text { to }-0.06)^{* *}$ & $0.74(-0.06$ to 1.55$)$ \\
\hline & Cognition-age left education & $0.02(-0.19$ to 0.21$)$ & $-0.03(-0.15$ to 0.09$)$ & $0.71(-0.02$ to 1.45$)$ \\
\hline & Cognition-chronic illnesses & $0.03(-0.20$ to 0.25$)$ & $-0.13(-0.25 \text { to }-0.03)^{*}$ & $0.19(-0.43$ to 0.85$)$ \\
\hline & Cognition-exercise & $0.01(-0.16$ to 0.18$)$ & $0.06(-0.04$ to 0.16$)$ & $-0.14(-0.79$ to 0.65$)$ \\
\hline \multicolumn{5}{|c|}{ Rate of change } \\
\hline & Intercept $t^{\mathrm{d}}$ & $-0.04(-0.07 \text { to }-0.02)^{* * *}$ & $-0.01(-0.01$ to 0.002$)$ & $0.03(0 \text { to } 0.06)^{*}$ \\
\hline & Cognition & $0.01(-0.02$ to 0.05$)$ & $0.01(-0.01$ to 0.02$)$ & $-0.10(-0.30$ to 0.07$)$ \\
\hline & Male & $0.02(-0.01$ to 0.04$)$ & $-0.01(-0.02 \text { to }-0.003)^{* *}$ & $0.02(0$ to 0.05$)$ \\
\hline & Smoking ${ }^{c}$ & $0.02(0.003 \text { to } 0.04)^{*}$ & $-0.002(-0.01$ to 0.01$)$ & $<0.001(-0.03$ to 0.03$)$ \\
\hline & Social class ${ }^{c}$ & $0.001(-0.02$ to 0.03$)$ & -0.01 ( -0.01 to 0.001$)$ & $-0.003(-0.03$ to 0.02$)$ \\
\hline & Age left education ${ }^{c}$ & $0.001(-0.03$ to 0.03$)$ & $-0.002(-0.01$ to 0.01$)$ & $-0.002(-0.03$ to 0.02$)$ \\
\hline & No. of chronic illnesses ${ }^{c}$ & $-0.004(-0.03$ to 0.02$)$ & $-0.01(-0.02 \text { to }-0.003)^{*}$ & $0.02(-0.001$ to 0.04$)$ \\
\hline & Exercise $^{c}$ & $-0.01(-0.03$ to 0.02$)$ & $-0.01(-0.01$ to 0.003$)$ & $0.01(-0.01$ to 0.04$)$ \\
\hline & Cognition-sex & $-0.01(-0.04$ to 0.01$)$ & 0.01 ( -0.01 to 0.02$)$ & $-0.05(-0.23$ to 0.11$)$ \\
\hline & Cognition-smoking & $-0.03(-0.05 \text { to } 0)^{*}$ & $-0.002(-0.02$ to 0.01$)$ & $0.13(-0.05$ to 0.31$)$ \\
\hline & Cognition-social class & $0.001(-0.03$ to 0.03$)$ & $0.02(-0.002$ to 0.03$)$ & $-0.12(-0.35$ to 0.11$)$ \\
\hline & Cognition-age left education & 0.001 ( -0.03 to 0.03$)$ & $0.001(-0.01$ to 0.02$)$ & $-0.10(-0.28$ to 0.07$)$ \\
\hline & Cognition-chronic illnesses & $-0.02(-0.05$ to 0.02$)$ & $0.01(-0.01$ to 0.02$)$ & $-0.04(-0.21$ to 0.14$)$ \\
\hline & Cognition-exercise & $0.01(-0.02$ to 0.04$)$ & $-0.001(-0.02$ to 0.01$)$ & $-0.002(-0.21$ to 0.17$)$ \\
\hline \multicolumn{5}{|c|}{ Variance components ${ }^{\mathrm{e}}$} \\
\hline Level 1 & Within-person & 1.83 & 1.68 & 1.75 \\
\hline Level 2 & In initial status & 1.59 & 1.31 & 1.67 \\
\hline Level 2 & In rate of change & 0 & 0.001 & 0.01 \\
\hline
\end{tabular}


Goodness of fit $^{\mathrm{f}}$

\begin{tabular}{|c|c|c|c|}
\hline Deviance ( $-2 \mathrm{LL})$ & 32944 & 63639 & 11384 \\
\hline AIC & 33006 & 63701 & 11446 \\
\hline BIC & 33225 & 63941 & 11632 \\
\hline
\end{tabular}

LL, Log-likelihood; AIC, Akaike's Information Criterion; BIC, Bayesian Information Criterion.

Data are given as regression coefficient $(95 \%$ confidence interval).

a Note: the covariance component is fixed at 0 .

b The intercept of the 'initial status' is the predicted average depressive symptom score at time 0 , with all other covariates held at 0 . In each age group, time is centered on the age at the start of that group. Therefore these intercepts represent the model-predicted average depression score at the ages of 50, 60 and 80 years, respectively.

${ }^{c}$ For each of these ordinal covariates, the coefficients represent the difference in depressive symptom score for a one-category increase in the covariates as shown in Table 1 (i.e. non-smoker, lower social class, older age at leaving education, more chronic illnesses, more exercise)

${ }^{d}$ The intercept of the rate of change is the average slope of depressive symptoms-on-time with all covariates held at zero. In each age group, time is centred on the age at the start of that group. Therefore these intercepts represent the model-predicted average slope of depressive symptoms-on-time at the ages of 50, 60 and 80 years, respectively.

${ }^{\mathrm{e}}$ The within-person variance is the overall residual variance, here the variance in depressive symptoms that is not explained by the model. The level-2 variance components are betweenperson variances. The initial status component is the variance of individuals' intercepts about the intercept of the average person. Likewise, the rate of change component is the variance of individual slopes about the slope of the average person.

${ }^{\mathrm{f}}$ Deviance is the difference in log-likelihood between the fitted model and the ideal saturated model. The AIC and BIC are essentially versions of the deviance penalized for the number of terms in the model. These are not all on an absolute scale, but the lower the number the better the fit.

${ }^{*} p<0.05, * * p<0.01, * * * p<0.001$
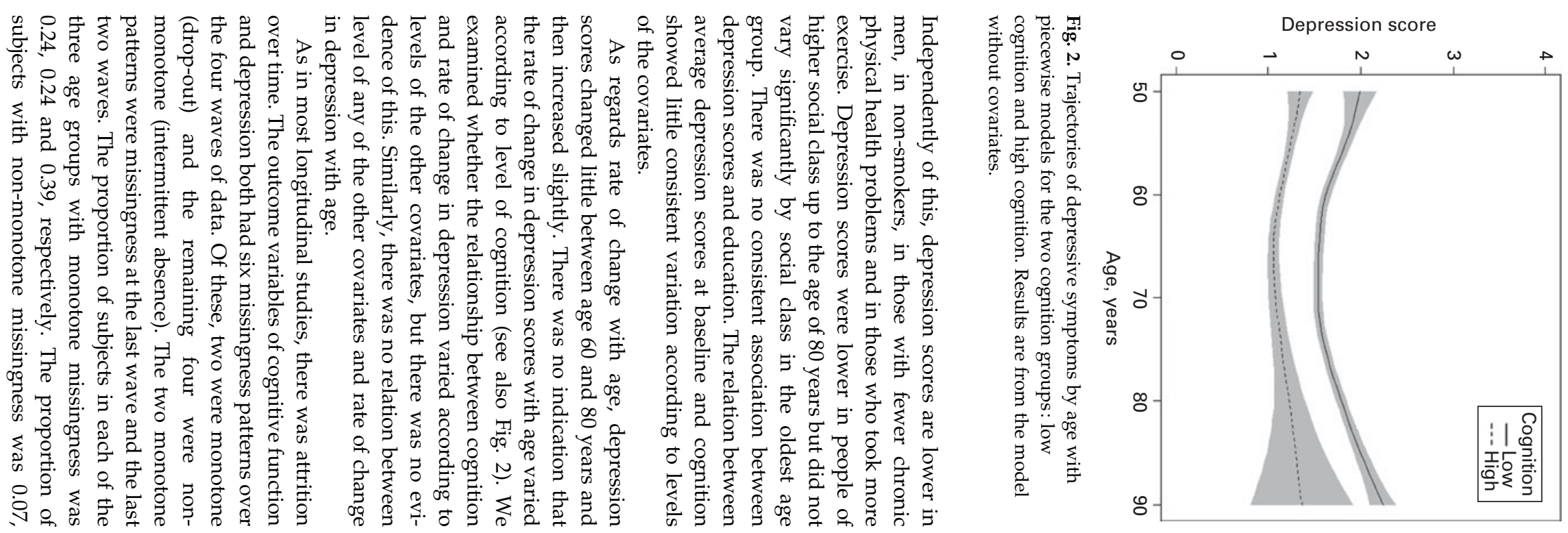
0.07 and 0.05 , respectively. We tested the effect of each missingness pattern on the linear growth parameters. None of the non-monotone patterns had a significant effect on either the initial status or the rate of change of the outcomes in any age group, using growth models that did not include the covariates. This suggests that the occurrence of non-monotone missingness was completely at random. In addition, since there were relatively few cases of non-monotone missingness, we judged this ignorable in the sense that it would not bias inferential results. Neither of the two monotone patterns had a significant effect on the rate of change of the outcomes in any age group, but both had a significant effect on the initial status for all three age groups, using growth models that did not include the covariates. However, this significance became borderline (at the $1 \%$ level) when the covariates were included in the model. This suggests that the occurrence of monotone missingness was random and covariate dependent. We judged this ignorable when the covariates were included in the model.

\section{Discussion}

In this study of people aged 50 to over 90 years, higher levels of depressive symptoms at baseline were associated with poorer cognition, except in the oldest age group. Depressive symptoms were associated with a slightly faster rate of cognitive decline over the 6-year follow-up period in people aged 60-80 years, but there was no such association in other age groups, though there was a similar-sized but non-significant effect in the age 50-60 years group. There was no evidence for an effect in the other direction: depressive symptoms changed little with increasing age, and cognition was not associated with the rate at which these symptoms changed over time. We found no indication that any of the covariates - sex, social class, education, number of chronic physical conditions, smoking and exercise - had an effect on the trajectories of cognitive decline or depressive symptoms.

Existing evidence on whether depression is a risk factor for cognitive decline is inconsistent, with some studies reporting positive findings (Yaffe et al. 1999; Paterniti et al. 2002; Wilson et al. 2004) but others finding no association (Dufouil et al. 1996; Henderson et al. 1997) or an association in subgroups only (Bassuk et al. 1998; Geerlings et al. 2000; Ng et al. 2009). Here, we were able to examine a measure of cognition based on performance on five tests, repeated four times over an approximate 6-year follow-up period. Cognitive decline was apparent from age 60 years and its trajectory accelerated with age, but being more depressed was only linked with the rate of cognitive decline in people aged $60-80$ years. However, we note that the effect sizes in the age 60-80 and age 50-60 years groups are similar - being -0.26 and -0.21 , respectively - and that the significance of the result in the age 60-80 years group occurs in part because this age group is larger and therefore has greater power.

Evidence from middle-aged adults suggests that those with poorer cognitive function earlier in life are more likely to experience high levels of psychological distress and have an increased risk of being diagnosed with depression, generalized anxiety and indeed the whole range of mental disorders (Gale et al. 2008, 2009, 2010). As cognitive performance at older ages is strongly reflective of peak prior ability (Deary et al. 2000), one might also expect that in older people better cognition would predict a more favourable trajectory of depressive symptoms. In the present study, however, on average, depressive symptoms changed little with age and there was no indication that this trajectory varied according to cognition. It is possible that our ability to detect change in depressive symptoms was hindered by the narrow range of potential scores ( 0 to 8 ) that could be achieved with the abbreviated version of the CES-D used here. However, it is worth noting that in previous studies that used different versions of the CES-D, a significant association between depressive symptoms and cognitive decline was found where the range of possible scores was 0 to 10 (Wilson et al. 2004), while where scores for depression had a potential range of 0 to 80 there was no association (Dufouil et al. 1996). Scores on the eightitem version used in the present study correlate very highly (0.93) with scores on the original 20-item version (Melchior et al. 1993), validating that this shorter version captures depressive symptoms as well as the longer version.

We found no association between age at leaving full-time education and trajectories of either cognitive decline or depressive symptoms. Most prior evidence on this has been based on smaller samples and on measurements made at two time points only. Of the few studies where cognitive change was assessed over at least three time points, some found no link with education (Christensen et al. 2001; Van Dijk et al. 2008; Wilson et al. 2009), and others that the association varied according to sex (Colsher \& Wallace, 1991) or cognitive domain assessed (Alley et al. 2007). Previous studies that have examined the relationship between education and the trajectory of depressive symptoms have found no link between level of education and the course of symptoms (Wilson et al. 2008; Penninx et al. 2011). It may be that education and perhaps cognition are more strongly predictive of onset of mental disorder than they are of its prognosis.

Evidence from randomized controlled trials in older people suggests that exercise may be beneficial for 
some aspects of cognition (Angevaren et al. 2008) and depressive symptoms (Blake et al. 2009), but there is a shortage of large, methodologically robust trials and follow-up periods were generally short. We observed no protective effect of exercise on the trajectories of cognitive decline and depressive symptoms over a 6-year period.

The strengths of our study are the sample size, the fact that it is representative of the communitydwelling English population aged 50 years and over (Taylor et al. 2003) and the use of a measure of cognition based on assessment of several cognitive domains. There are also some weaknesses. First, the relatively short interval between waves may have hindered our ability to detect change in cognition, particularly in younger participants. Second, depressive symptoms were assessed with an eight-item version of the CES-D. This measure is closely comparable with the original in reliability and the dimensions it assesses (Turvey et al. 1999) but the narrow potential range of scores may mean that our results underestimate the impact of depression on cognitive decline and the extent to which cognition and other factors influence depression.

In this large study of people aged 50 years and over, cognition and depressive symptoms were assessed four times over a 6-year period and showed significant cross-sectional associations. Being more depressed led to a slight acceleration in cognitive decline, which was significant only in people aged $60-80$ years. There was no support for the hypothesis that there might be reciprocal dynamic influences between cognitive ability and depressive symptoms.

\section{Acknowledgements}

The HALCyon (Healthy Ageing across the Life Course) collaborative research programme is funded by the New Dynamics of Ageing (NDA) programme, a joint 7-year initiative of five UK Research Councils (no. RES-353-25-0001). This work was undertaken by The University of Edinburgh Centre for Cognitive Ageing and Cognitive Epidemiology, part of the crosscouncil Lifelong Health and Wellbeing Initiative (no. G0700704/84698).

\section{Declaration of Interest}

None.

\section{References}

Alley D, Suthers K, Crimmins E (2007). Education and cognitive decline in older americans: results from the AHEAD sample. Research on Aging 29, 73-94.
Angevaren M, Aufdemkampe G, Verhaar HJ, Aleman A, Vanhees L (2008). Physical activity and enhanced fitness to improve cognitive function in older people without known cognitive impairment. Cochrane Database of Systematic Reviews. Issue 2. Art no. CD005381. doi:10.1002/14651858.CD005381.pub2.

Anstey K, Christensen H (2000). Education, activity, health, blood pressure and apolipoprotein $\mathrm{E}$ as predictors of cognitive change in old age: a review. Gerontology 46, 163-177.

Auperin A, Berr C, Bonithon-Kopp C, Touboul PJ, Ruelland I, Ducimetiere P, Alperovitch A (1996). Ultrasonographic assessment of carotid wall characteristics and cognitive functions in a community sample of 59- to 71-year-olds. The EVA Study Group. Stroke 27, 1290-1295.

Bassuk SS, Berkman LF, Wypij D (1998). Depressive symptomatology and incident cognitive decline in an elderly community sample. Archives of General Psychiatry 55, 1073-1081.

Blake H, Mo P, Malik S, Thomas S (2009). How effective are physical activity interventions for alleviating depressive symptoms in older people? A systematic review. Clinical Rehabilitation 23, 873-887.

Bond J, Dickinson HO, Matthews F, Jagger C, Brayne C (2006). Self-rated health as a predictor of death, functional and cognitive impairment: a longitudinal cohort study. European Journal of Ageing 3, 193-206.

Chang-Quan H, Xue-Mei Z, Bi-Rong D, Zhen-Chan L, Ji-Rong Y, Qing-Xiu L (2010). Health status and risk for depression among the elderly: a meta-analysis of published literature. Age and Ageing 39, 23-30.

Christensen H, Griffiths K, Mackinnon A, Jacomb P (1997). A quantitative review of cognitive deficits in depression and Alzheimer-type dementia. Journal of the International Neuropsychology Society 3, 631-651.

Christensen H, Hofer SM, Mackinnon AJ, Korten AE, Jorm AF, Henderson AS (2001). Age is no kinder to the better educated: absence of an association investigated using latent growth techniques in a community sample. Psychological Medicine 31, 15-28.

Colsher PL, Wallace RB (1991). Longitudinal application of cognitive function measures in a defined population of community-dwelling elders. Annals of Epidemiology 1, 215-230.

de Beurs E, Beekman A, Geerlings S, Deeg DJ, Van Dyck R, Van Tilburg W (2001). On becoming depressed or anxious in late life: similar vulnerability factors but different effects of stressful life events. British Journal of Psychiatry 179, 426-431.

Deary IJ, Whalley LJ, Lemmon H, Crawford JR, Starr JM (2000). The stability of individual differences in mental ability from childhood to old age: follow-up of the 1932 Scottish Mental Survey. Intelligence 28, 49-55.

Dufouil C, Fuhrer R, Dartigues JF, Alperovitch A (1996). Longitudinal analysis of the association between depressive symptomatology and cognitive deterioration. American Journal of Epidemiology 144, 634-641.

Fonda SJ, Herzog AR (2001). Patterns and risk factors of change in somatic and mood symptoms among older adults. Annals of Epidemiology 11, 361-368. 
Fuhrer R, Antonucci TC, Gagnon M, Dartigues JF, Barberger-Gateau P, Alperovitch A (1992). Depressive symptomatology and cognitive functioning: an epidemiological survey in an elderly community sample in France. Psychological Medicine 22, 159-172.

Gale CR, Batty GD, Tynelius P, Deary IJ, Rasmussen F (2010). Intelligence in early adulthood and subsequent hospitalisation and admission rates for the whole range of mental disorders: longitudinal study of 1,049,663 men. Epidemiology 21, 70-77.

Gale CR, Deary IJ, Boyle SH, Barefoot J, Mortensen LH, Batty GD (2008). Cognitive ability in early adulthood and risk of five specific psychiatric disorders in mid life: the Vietnam Experience Study. Archives of General Psychiatry 65, 1410-1418.

Gale CR, Hatch SL, Batty GD, Deary IJ (2009). Intelligence in childhood and risk of psychological distress in adulthood: the 1958 National Child Development Survey and the 1970 British Cohort Study. Intelligence 37, 592-599.

Gale CR, Sayer AA, Cooper C, Dennison EM, Starr JM, Whalley LJ, Gallacher JE, Ben-Shlomo Y, Kuh D, Hardy R, Craig L, Deary IJ (2011). Factors associated with symptoms of anxiety and depression in five cohorts of community-based older people: the HALCyon (Healthy Ageing across the Life Course) Programme. Psychological Medicine 41, 2057-2073.

Ganguli M, Du Y, Dodge HH, Ratcliff GG, Chang CC (2006). Depressive symptoms and cognitive decline in late life: a prospective epidemiological study. Archives of General Psychiatry 63, 153-160.

Gatz JL, Tyas SL, St John P, Montgomery P (2005). Do depressive symptoms predict Alzheimer's disease and dementia? Journals of Gerontology Series A Biological Science and Medical Science 60, 744-747.

Geerlings MI, Schoevers RA, Beekman AT, Jonker C, Deeg DJ, Schmand B, Adèr HJ, Bouter LM, Van Tilberg W (2000). Depression and risk of cognitive decline and Alzheimer's disease. Results of two prospective community-based studies in The Netherlands. British Journal of Psychiatry 176, 568-575.

Hastie T, Tibsharani R (1999). Generalized Additive Models. Chapman \& Hall: New York.

Hedeker D, Gibbons RD (1997). Application of randomeffects pattern-mixture models for missing data in longitudinal studies. Psychological Methods 2, 64-78.

Henderson AS, Korten AE, Jacomb PA, Mackinnon AJ, Jorm AF, Christensen H, Rodgers B (1997). The course of depression in the elderly: a longitudinal community-based study in Australia. Psychological Medicine 27, 119-129.

Kay DW, Henderson AS, Scott R, Wilson J, Rickwood D, Grayson DA (1985). Dementia and depression among the elderly living in the Hobart community: the effect of the diagnostic criteria on the prevalence rates. Psychological Medicine 15, 771-788.

Koster A, Bosma H, Kempen GI, Penninx BW, Beekman AT, Deeg DJ, van Eijk JT (2006). Socioeconomic differences in incident depression in older adults: the role of psychosocial factors, physical health status, and behavioral factors. Journal of Psychosomatic Research 61, 619-627.
Koster A, Penninx BW, Bosma H, Kempen GI, Newman AB, Rubin SM, Satterfield S, Atkinson HH, Ayonayon HN, Rosano C, Yaffe K, Harris TB, Rooks RN, van Eijk JT, Kritchevsky SB (2005). Socioeconomic differences in cognitive decline and the role of biomedical factors. Annals of Epidemiology 15, 564-571.

Kramer AF, Erickson KI, Colcombe SJ (2006). Exercise, cognition, and the aging brain. Journal of Applied Physiology 101, 1237-1242.

La Rue A, Swan GE, Carmelli D (1995). Cognition and depression in a cohort of aging men: results from the Western Collaborative Group Study. Psychology and Aging 10, 30-33.

Mangione CM, Seddon JM, Cook EF, Krug Jr JH, Sahagian CR, Campion EW, Glynn RJ (1993). Correlates of cognitive function scores in elderly outpatients. Journal of the American Geriatrics Society 41, 491-497.

Marmot M, Nazroo J, Banks J, Blundell R, Erens B, Lessof C, Huppert FA (2011). English Longitudinal Study of Ageing: wave $0(1998,1999$ and 2001) and waves 1-4 (2002-2009) [computer file], 15th edition, SN: 5050. UK Data Archive: Colchester.

Melchior LA, Huba GJ, Brown VB, Reback CJ (1993). A short depression index for women. Educational and Psychological Measurement 53, 1117-1125.

Muthén LK, Muthén BO (1998-2010). Mplus User's Guide, 6th edn. Muthén and Muthén: Los Angeles.

Ng TP, Niti M, Zaw MH, Kua EH (2009). Depressive symptoms and incident cognitive impairment in cognitively well-functioning older men and women. Journal of the American Geriatrics Society 57, 1058-1063.

Nooyens AC, van Gelder BM, Verschuren WM (2008). Smoking and cognitive decline among middle-aged men and women: the Doetinchem Cohort Study. American Journal of Public Health 98, 2244-2250.

Office for National Statistics (2005). The National Statistics Socioeconomic Classification. User Manual. Palgrave Macmillan: Basingstoke.

Paterniti S, Verdier-Taillefer MH, Dufouil C, Alperovitch A (2002). Depressive symptoms and cognitive decline in elderly people. Longitudinal study. British Journal of Psychiatry 181, 406-410.

Penninx BW, Nolen WA, Lamers F, Zitman FG, Smit JH, Spinhoven P, Cuijpers P, de Jong PJ, van Marwijk HW, der Meer KV, Verhaak P, Laurant MG, de Graaf R, Hoogendijk WJ, van der Wee N, Ormel J, Van Dyke R, Beekman AT (2011). Two-year course of depressive and anxiety disorders: results from the Netherlands Study of Depression and Anxiety (NESDA). Journal of Affective Disorders 133, 76-85.

Perrino T, Mason CA, Brown SC, Spokane A, Szapocznik J (2008). Longitudinal relationships between cognitive functioning and depressive symptoms among Hispanic older adults. Journals of Gerontology Series B Psychological Sciences and Social Sciences 63, 309-317.

Rabbitt P, Donlan C, Watson P, McInnes L, Bent N (1995). Unique and interactive effects of depression, age, socioeconomic advantage, and gender on cognitive performance of normal healthy older people. Psychology and Aging 10, 307-313. 
Ruppert D, Wand MP, Carroll R (2003). Semiparametric Regression. Cambridge University Press: Cambridge.

Scherr PA, Albert MS, Funkenstein HH, Cook NR, Hennekens CH, Branch LG, White LR, Taylor JO, Evans DA (1988). Correlates of cognitive function in an elderly community population. American Journal of Epidemiology 128, 1084-1101.

Steffick DE; The HRS Working Group (2000).

Documentation of affective functioning measures in the Health and Retirement Study. HRS/AHEAD

Documentation Report DR-005 (http:/ /

hrsonline.isr.umich.edu/sitedocs/userg/dr-005.pdf)

Accessed 15 December 2011

Taylor R, Conway L, Calderwood L, Lessof C (2003). Methodology. In Health, Wealth and Life-Styles of the Older Population in England: the 2002 English Longitudinal Study of Ageing (ed. M. Marmot, J. Banks, R. Blundell, C. Lessof and J. Nazroo), pp. 357-374. Institute of Fiscal Studies: London.

Turvey CL, Wallace RB, Herzog R (1999). A revised CES-D measure of depressive symptoms and a DSM-based measure of major depressive episodes in the elderly. International Psychogeriatrics 11, 139-148.

Van Dijk KR, Van Gerven PW, Van Boxtel MP, Van der Elst W, Jolles J (2008). No protective effects of education during normal cognitive aging: results from the 6-year follow-up of the Maastricht Aging Study. Psychology and Aging 23, 119-130.

Wilson RS, Arnold SE, Beck TL, Bienias JL, Bennett DA (2008). Change in depressive symptoms during the prodromal phase of Alzheimer disease. Archives of General Psychiatry 65, 439-445.

Wilson RS, Barnes LL, Mendes de Leon CF, Aggarwal NT, Schneider JS, Bach J, Pilat J, Beckett LA, Arnold SE, Evans DA, Bennett DA (2002). Depressive symptoms, cognitive decline, and risk of AD in older persons. Neurology 59, 364-370.

Wilson RS, Hebert LE, Scherr PA, Barnes LL, Mendes de Leon CF, Evans DA (2009). Educational attainment and cognitive decline in old age. Neurology 72, 460-465.

Wilson RS, Mendes de Leon CF, Bennett DA, Bienias JL, Evans DA (2004). Depressive symptoms and cognitive decline in a community population of older persons. Journal of Neurology, Neurosurgery and Psychiatry 75, 126-129.

Woods SN (2006). Generalized Additive Models: An Introduction with R. Chapman \& Hall/CRC: Boca Raton.

Yaffe K, Blackwell T, Gore R, Sands L, Reus V, Browner WS (1999). Depressive symptoms and cognitive decline in nondemented elderly women: a prospective study. Archives of General Psychiatry 56, 425-430. 